\title{
Delayed reinforcement: Effect of a brief signal on behavior maintained by a variable-ratio schedule
}

\author{
RALPH W. RICHARDS and DOUGLAS B. RICHARDSON \\ Colorado State University, Fort Collins, Colorado
}

\begin{abstract}
In alternating phases, pigeons received immediate and delayed food reinforcement under a variable-ratio schedule for pecking a key. A 3-sec delay produced less disruption in responding if the entire delay interval was signaled rather than unsignaled. Effects of signaling different .5 -sec portions of the delay interval were also examined. Most birds showed little or no decrease in responding if the signal occurred at the beginning of the delay interval, but showed a substantial decrease in responding if the signal occurred in the middle or at the end of the delay interval.
\end{abstract}

A major operational component of the contingency-ofreinforcement concept is the time that elapses between emission of the operant response and receipt of the stimulus consequence. Early research with delayed food reward (e.g., Grice, 1948; Perin, 1943; Spence, 1947) suggested that rats learn faster if an exteroceptive stimulus is provided during the delay interval. In subsequent studies (e.g., Azzi, Fix, Keller, \& Rocha e Silva, 1964; Ferster, 1953; Lattal, 1984; Pierce, Hanford, \& Zimmerman, 1972; Richards, 1981; Richards \& Hittesdorf, 1976; Sizemore \& Lattal, 1978; Williams, 1976), researchers have examined effects on responding maintained by intermittent reinforcement. Currently, the most common methodology involves pigeons, keypecking, food reward, and a variable-interval schedule. Employing this methodology, several researchers (e.g., Lattal, 1984; Richards, 1981) have found response rates to be much higher if the delay interval is signaled rather than unsignaled. Schaal and Branch (1988) reported a similar finding with a delay signal that did not persist for the entire delay interval. In fact, immediate reinforcement and delayed reinforcement of either 3 or $9 \mathrm{sec}$ produced comparable response rates when only the first $.5 \mathrm{sec}$ of the delay interval was signaled; responding was reduced substantially when the entire 3- or 9-sec delay interval was unsignaled. A .5-sec signal did not prevent decreases in responding with a $27-$ sec delay, but a subsequent study (Schaal \& Branch, 1990) showed that the impact of even this delay duration could be lessened by increasing the delay signal's duration.

In the present experiment, we examined the generality of the brief-signal results obtained by Schaal and Branch (1988) with a 3-sec delay of reinforcement. There were three major concerns: the type of delay signal, the temporal location of the signal, and the underlying schedule of reinforcement. The signal employed by Schaal and Branch was a change in color on the pecking key. Rather

Douglas B. Richardson is currently a graduate student in the Department of Behavioral Neuroscience, University of Pittsburgh, Pittsburgh, PA 15260. Reprints may be obtained from Ralph W. Richards, Department of Psychology, Colorado State University, Fort Collins, CO 80523. than change anything on the key, in the present study we merely added an off-key visual stimulus. The question of whether or not a similar effect would occur with an offkey stimulus seemed especially relevant in view of the extensive autoshaping literature (e.g., Hearst \& Jenkins, 1974; Locurto, Terrace, \& Gibbon, 1981). A second concern was whether Schaal and Branch's (1988) results depended on the signal occurring at the very beginning of the delay interval. To address this issue, we manipulated the temporal location of the signal within the delay inter$\mathrm{val}$. The final concern was whether or not Schaal and Branch's findings could be replicated with a different reinforcement schedule-specifically, a variable-ratio schedule. Although the latter concern may appear trivial, it should be noted that some independent variablesincluding various drugs (see, e.g., Dews, 1955; Kelleher \& Morse, 1964), magnitude of reward (Reed, 1991), and visual stimuli (Robinson \& Shelley, 1974; Schachtman \& Reed, 1990)-produce qualitatively different effects on behavior maintained by interval versus ratio schedules.

\section{METHOD}

Subjects

Four adult female White Carneaux pigeons with previous autoshaping experience were maintained at $80 \%-85 \%$ of their free-feeding weights.

\section{Apparatus}

The conditioning chamber had internal dimensions of $35.5 \times 37 \times$ $36 \mathrm{~cm}$ and was constructed primarily of white-painted plywood. A hinged Plexiglas door served as one wall. Another wall was the metal intelligence panel that contained a houselight, a row of three circular response keys ( $2.6 \mathrm{~cm}$ in diameter), and a food aperture. The houselight, an 1820 bulb encased in milky-white plastic, was centered between the sidewalls and located $30 \mathrm{~cm}$ above the wire-mesh subfloor. Only the middle key was used; it was illuminated green by an 1820 bulb from an in-line display cell, and its center was $23 \mathrm{~cm}$ above the subfloor. The key remained illuminated during the delay interval but was darkened during the reinforcement period. The delay interval could be signaled by turning on the red pilot light (1820 bulb) mounted on the back wall $(18.5 \mathrm{~cm}$ from the door and $29 \mathrm{~cm}$ above the subfloor). The $5 \times 5 \mathrm{~cm}$ food aperture, directly below the center key and $18.5 \mathrm{~cm}$ from the subfloor, permit- 
ted access to mixed grain for $4 \mathrm{sec}$ when the solenoid-operated food tray was raised. The chamber was placed inside a wooden shell. Two small fans provided good ventilation and some masking of extraneous noises.

An Apple Ile microcomputer and a Med Associates interface were used to present stimuli, time events, and record responses.

\section{Procedure}

Due to the pigeons' prior history, no special training was needed to establish keypecking. The size of the variable-ratio schedule was increased gradually to 50 for S-3327 and S-7293 and to 100 for S-7454 and S-3813. Each session began and ended in darkness, but at no time during a session was the houselight turned off. Sessions terminated following the 60th reinforcer or following the first reinforcer delivered after $1 \mathrm{~h}$, whichever occurred first.

There were 13 phases of training. Immediate reinforcement occurred in the odd-numbered phases. Depending on the bird, there were between 65 and 105 sessions in Phase 1; the remaining immediate-reinforcement phases each contained 18 sessions. Each of the odd-numbered phases contained 42 sessions and involved a 3-sec delay of reinforcement. In Phases 2 and 10, the entire delay interval was unsignaled (UD). In Phase 12, the red pilot light was illuminated for the entire delay interval (SD). The pilot light was illuminated for only .5 sec in Phases 4, 6 , and 8 . In these three phases, the signal occurred at the beginning (E-SD, early signal delay), in the middle (M-SD, middle signal delay), and at the end (L-SD, late signal delay) of each delay interval.

It should be noted that all pigeons received the various brief-signal conditions in the same order. Although some sort of counterbalancing could easily have been employed, our first concern was to replicate Schaal and Branch's (1988) findings. Thus, rather than risk potential carryover effects once the signal had been directly paired with the food and presumably become a strong conditioned reinforcer, we decided to present the brief-signal conditions in an order that decreased the likelihood that behavior observed in later phases could be attributed to the signal's becoming a stronger conditioned reinforcer in earlier phases.

\section{RESULTS}

The connected $\times s$ in Figure 1 represent each bird's mean response rate during the final nine sessions of each phase. An indication of the stability of responding may be obtained by examining mean response rates during the last three three-session blocks, indicated in order of occurrence by oval, rectangle, and diamond symbols. Neither the responses made during the delay interval nor the delay-interval time was included in the calculation of response rates. Figure 1 shows that changing the procedure from immediate reinforcement in Phase 1 to totally unsignaled delayed reinforcement in Phase 2 produced a large decrease in each bird's response rate; response rates increased on reintroduction of immediate reinforcement in Phase 3. A similar pattern occurred in Phases 9-11, although the magnitude of change was lessened for S-7454.

When a .5 -sec signal occurred at the beginning of the delay intervals (E-SD), only S-3327 showed a large decrease in responding; S-7293 and S-7454 showed no decrease, and S-3813 showed, at most, a very slight decrease. In contrast, all birds showed a large decrease in responding when the brief signal was delivered in the middle of the delay interval (M-SD) and at the end of the delay interval (L-SD).

Changing from immediate reinforcement in Phase 11 to totally signaled delayed reinforcement (SD) in Phase 12 produced some decrease in responding for 3 birds (exception, S-7293). In seven of the eight possible withinsubjects comparisons, absolute response rates were higher under SD than under UD. Unfortunately, more detailed comparisons of response rates among the various delay procedures are problematic, owing to changing baseline response rates of some birds across the numerous phases of immediate reinforcement.

\section{DISCUSSION}

Keypecking of pigeons produced food either immediately upon completion of the requirements of a variable-ratio schedule or $3 \mathrm{sec}$ later. The 3-sec delay had different effects, depending on stimulus events within the delay interval. For example, response rates were higher when a pilot light at the rear of the chamber was illuminated throughout the delay interval than they were when no stimulus change occurred during the delay interval. This signaled-unsignaled difference confirms previous research (e.g., Lattal, 1984; Richards, 1981) conducted with a variable-interval baseline schedule. Schaal and Branch (1988), who also employed a variable-interval schedule, reported that delaying reinforcement for $3 \mathrm{sec}$ did not decrease responding if there was a brief change in the stimulus on the key at the onset of the delay interval. With a variable-ratio schedule and an off-key delay signal, we obtained a similar finding with 3 of 4 pigeons. Clearly, Schaal and Branch's finding is neither an artifact of their use of an insensitive baseline schedule nor a mere byproduct of autoshaping owing to their use of an on-key delay signal. However, it might be useful to systematically compare the enhancing effects of signals with various physical characteristics. Perhaps our delay signal was relatively nonsalient, which could explain why 1 of our subjects (S-3327) did show a large decrease in responding with the brief signal at the beginning of the delay interval.

The present study showed that the effectiveness of the brief delay signal depended on its location within the delay interval. Most birds showed little change in responding when onset of the signal and onset of the delay interval coincided, yet showed substantial reductions in responding when onset of the signal followed onset of the delay interval by either 1.25 or $2.5 \mathrm{sec}$. Conditioned reinforcement (e.g., Spence, 1947) may relate to these findings. Since the delay signal predicted food and was paired with food, it should become a conditioned reinforcer. All other things being equal, lower response rates would be expected with delayed conditioned reinforcement (M-SD and L-SD) as opposed to immediate conditioned reinforcement (E-SD). However, moving the signal further away from the onset of the delay interval also moved it closer to the food reward, which should have increased its potency as a conditioned reinforcer. Although the suspected increase in the signal's potency as a conditioned reinforcer may not have been sufficient to counteract the effect produced by delaying its delivery, this should be viewed as a post hoc explanation.

Richards (1981) employed the concepts of adventitious reinforcement, competing behavior, and stimulus generalization in a speculative analysis of why responding might be more rapid when the entire delay interval is signaled rather than unsignaled. The suggestion was that adventitious reinforcement would strengthen competing behavior, regardless of whether or not the delay interval was signaled, but that the competing behavior would generalize less to nondelay portions of the session when acquired during a distinctive signaled delay period. This analysis, although successfully extended by Schaal and Branch (1990) to their findings, fails to account for the present results involving the E-SD, M-SD, and L-SD procedures. Of these brief-delay procedures, E-SD assured the greatest similarity between nondelay portions of the session and the end of the delay interval, where adventitious reinforcement would occur. This means that the most generalization of competing behavior to nondelay portions of the session should have occurred with the E-SD procedure, which implies that this signaled-delay procedure would produce the lowest rate of keypecking. In fact, the E-SD procedure produced much less disruption of keypecking than did either the M-SD or L-SD procedures. 



Figure 1. Mean response rates during the last nine sessions of each phase (indicated by $\times s$ ). Mean response rates during the last three three-session blocks are indicated in order of occurrence by ovals, rectangles, and diamonds. 
In view of the recent resurgence of interest in animals' informationprocessing abilities (e.g., Roitblat, Bever, \& Terrace, 1984), future researchers may be expected to employ increasingly more cognitive perspectives in dealing with delayed reinforcement. Perhaps a delay signal is effective only to the extent that it marks the reinforced response (see Lieberman, McIntosh, \& Thomas, 1979) and improves subjects' perception of a cause-and-effect relationship between behavior and reward. In this regard, it would be interesting to examine the various delay procedures within the detection-of-causality methodology developed by Killeen and Smith (1984).

\section{REFERENCES}

Azzi, R., Fix, D. S. R., Keller, F. S., \& Rocha E Silva, M. I. (1964). Exteroceptive control of response under delayed reinforcement. Journal of the Experimental Analysis of Behavior, 7, 159-162.

DEws, P. B. (1955). Studies on behavior: II. The effects of pentobarbital, methamphetamine, and scopolamine on performances in pigeons involving discriminations. Journal of Pharmacology \& Experimental Therapeutics, 115, 380-389.

FERSTER, C. B. (1953). Sustained behavior under delayed reinforcement. Journal of Experimental Psychology, 45, 218-224.

GRICE, G. R. (1948). The relation of secondary reinforcement to delayed reward in visual discrimination learning. Journal of Experimental Psychology, 38, 1-16.

Hearst, E., \& Jenkins, H. M. (1974). Sign-tracking: The stimulusreinforcer relation and directed action. Austin, TX: Psychonomic Society.

Kelleher, R. T., Morse, W. H. (1964). Escape behavior and punished behavior. Federation Proceedings, 23, 808-817.

KILleEN, P. R., \& SMITH, J. P. (1984). Perception of contingency in conditioning: Scalar timing, response bias, and erasure of memory by reinforcement. Journal of Experimental Psychology: Animal Behavior Processes, 10, 333-345.

LATTAL, K. A. (1984). Signal functions in delayed reinforcement. Journal of the Experimental Analysis of Behavior, 42, 239-253.

Lieberman, D. A., McINTosh, D. C., \& Thomas, G. V. (1979). Learning when reward is delayed: A marking hypothesis. Journal of Experimental Psychology: Animal Behavior Processes, 5, 224-242.

Locurto, C. M., Terrace, H. S., \& GibBon, J. (EDs.) (1981). Autoshaping and conditioning theory. New York: Academic Press.
Perin, C. T. (1943). A quantitative investigation of the delay-ofreinforcement gradient. Journal of Experimental Psychology, 32, 37-51.

Pierce, C. H., Hanford, P. V., \& Zimmerman, J. (1972). Effects of different delay of reinforcement procedures on variable-interval responding. Journal of the Experimental Analysis of Behavior, 18, 141-146.

REED, P. (1991). Multiple determinants of the effects of reinforcement magnitude on free-operant response rates. Journal of the Experimental Analysis of Behavior, 55, 109-123.

RichARDs, R. W. (1981). A comparison of signaled and unsignaled delay of reinforcement. Journal of the Experimental Analysis of Behavior, 35, 145-152.

RichaRds, R. W., \& HitTesDoRf, W. M. (1976). Reinforcement delay: A parametric study of effects within a multiple schedule. Bulletin of the Psychonomic Society, 7, 303-305.

Robinson, P. W., \& SHELley, M. F. (1974). The effects of total darkness on schedule control. Journal of the Experimental Analysis of Behavior, 22, 391-400.

Roitblat, H. L., Bever, T. G., \& Terrace, H. S. (Eds.) (1984). Animal cognition. Hillsdale, NJ: Erlbaum.

SCHAAL, D. W., \& BRANCH, M. N. (1988). Responding of pigeons under variable-interval schedules of unsignaled, briefly signaled, and completely signaled delays to reinforcement. Journal of the Experimental Analysis of Behavior, 50, 33-54.

SCHAAL, D. W., \& BRANCH, M. N. (1990). Responding of pigeons under variable-interval schedules of signaled-delayed reinforcement: Effects of delay-signal duration. Journal of the Experimental Analysis of Behavior, 53, 103-121.

SCHACHTMAN, T. R., \& REED, P. (1990). The role of response-reinforcer correlation in signaled reinforcement effects. Animal Learning \& Behavior, 18, 51-58.

Sizemore, O. J., \& LATTAL, K. A. (1978). Unsignalled delay of reinforcement in variable-interval schedules. Journal of the Experimental Analysis of Behavior, 30, 169-175.

SPENCE, K. W. (1947). The role of secondary reinforcement in delayed reward learning. Psychological Review, 54, 1-8.

Williams, B. A. (1976). The effects of unsignalled delayed reinforcement. Journal of the Experimental Analysis of Behavior, 26, 441-449.

(Manuscript received April 8, 1991.) 